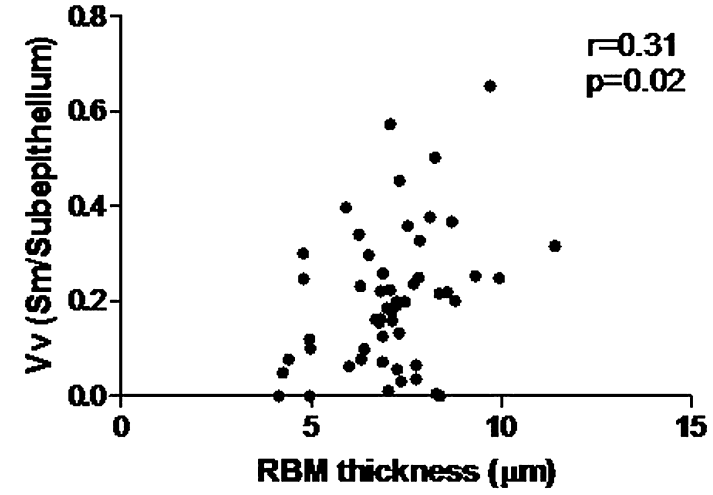

Abstract S87 Figure 1 Correlation between RBM and volume fraction of airway smooth muscle in asthma.

(bronchoscoped for upper airway symptoms) were included. All underwent fibreoptic bronchoscopy with endobronchial biopsies (EB). EB were processed to paraffin, and $5 \mu \mathrm{m}$ sections were cut and stained with haematoxylin and eosin and used to quantify RBM thickness, epithelial shedding and volume fraction $(\mathrm{Vv})$ of subepithelial smooth muscle indexed to submucosa.

Results Epithelial shedding was increased in atopic but not asthmatic subjects, $(p=0.02$ and $p=0.37$, respectively), and in children with asthma was correlated with exhaled nitric oxide $(r=0.4$, $\mathrm{p}=0.005)$. RBM thickness was increased in severe asthmatics compared to controls $(p<0.0001)$, but a trend only to increased thickness was seen in mild asthmatics compared to controls (median (range) values: $6(4.4-8.4)$ and $4(3.1-7.5) \mu \mathrm{m}$, respectively; $p=0.06)$. The $V_{v}$ of subepithelial airway smooth muscle was only increased in severe asthmatics compared to controls $(0.20(0-0.65)$ and $0.09(0-0.16)$, respectively; $\mathrm{p}=0.002)$. Interestingly, there was a positive relationship between RBM thickness and smooth muscle $\mathrm{Vv}$ fraction in asthmatics, but not in controls $(\mathrm{r}=0.31, \mathrm{p}=0.02$ and $\mathrm{r}=0.5, \mathrm{p}=0.07$, respectively) (Abstract S87 Figure 1).

Discussion We report for the first time a direct relationship between RBM thickness and airway smooth muscle mass in paediatric asthma. It is unknown if the relationship is causal, or both are driven by a common underlying process. Combinations of components of airway remodelling, rather than single factors, may prove to be more informative when phenotyping children with severe asthma.

\section{S88 MAST CELL MYOSITIS IS ASSOCIATED WITH PERSISTENT AIRFLOW LIMITATION (PAL) IN CHILDHOOD SEVERE ASTHMA (SA)}

doi:10.1136/thx.2010.150938.39

${ }^{1} \mathrm{C}$ J Bossley, ${ }^{2} \mathrm{~T}$ Oates, ${ }^{1} \mathrm{~N}$ Regamey, ${ }^{1} \mathrm{~L}$ Fleming, ${ }^{2} \mathrm{C}$ Lloyd, ${ }^{1} \mathrm{~A}$ Bush, ${ }^{1} \mathrm{~S}$ Saglani. ${ }^{1}$ Royal Brompton Hospital, London, UK; ${ }^{2}$ Imperial College, London, UK

Background Studies of airway inflammation and remodelling may help us to understand the pathophysiology of SA. Adult studies have shown mast cell inflammation within smooth muscle is specific to asthma and is associated with airway hyperresponsiveness (AHR). However, this has not been studied in childhood disease.

Hypothesis Children with SA have increased submucosal eosinophils and mast cells within smooth muscle compared to age-matched mild asthmatics and non-asthmatic controls.

Methods 75 children, mean age 11.8 (5.6-17.3) years, 53 with SA, 7 with mild/moderate asthma (MA) and 15 non-asthmatic controls (bronchoscoped for upper airway symptoms) were included. All underwent spirometry and bronchodilator reversibility, fractional exhaled nitric oxide (FeNO) measurement, fibreoptic bronchoscopy with bronchoalveolar lavage (BAL) and endobronchial biopsy (EB).
EB were stained for: eosinophils (congo red), neutrophils (neutrophil elastase), mast cells (mast cell tryptase); and reticular basement membrane (RBM) thickness, epithelial shedding and volume fraction $(\mathrm{Vv})$ of smooth muscle.

Results See Abstract S88 Table 1. Children with SA had significantly increased BAL and submucosal eosinophils compared to controls. There were no significant group differences in submucosal mast cells, but the presence of mast cells within smooth muscle exhibited a non-significant trend to be increased in SA and MA. Children with mast cells within smooth muscle were more likely to have PAL (post bronchodilator, post steroid trial $\mathrm{FEV}_{1}<80 \%$ predicted) $(p<0.05)$. The $\mathrm{VV}_{\mathrm{V}}$ of subepithelial tissue occupied by airway smooth muscle (ASM) was only increased in SA.

Abstract S88 Table 1 Airway inflammation and remodelling in severe, mild/moderate asthma and non asthmatic control subjects

\begin{tabular}{|c|c|c|c|c|}
\hline & $\begin{array}{l}\text { Severe asthma } \\
(n=53)\end{array}$ & $\begin{array}{l}\text { Mild/moderate } \\
\text { asthma }(\mathrm{n}=7)\end{array}$ & $\begin{array}{l}\text { Control } \\
(n=15)\end{array}$ & $\mathbf{p}$ \\
\hline BAL eosinophils \% & $2.7(1-51)$ & $0.7(0-27.7)$ & $0(0-5.7)$ & $<0.001$ \\
\hline BAL neutrophils \% & $3.3(0.3-73.7)$ & $1.7(0-7.3)$ & $2.7(0.6-14)$ & NS \\
\hline Mucosal eosinophils $\left(/ \mathrm{mm}^{2}\right)$ & $11.2(0-209.3)$ & $3.7(0-14.5)$ & $0(0-25.1)$ & 0.01 \\
\hline Mucosal neutrophils $\left(/ \mathrm{mm}^{2}\right)$ & $9.8(0-125.6)$ & $11.4(0-22.2)$ & $1.2(0-58.3)$ & NS \\
\hline Mucosal mast cells $\left(/ \mathrm{mm}^{2}\right)$ & $45.7(0-185)$ & $63.1(9.2-79.7)$ & $60.5(0-165.6)$ & NS \\
\hline Muscle mast cells $\left(/ \mathrm{mm}^{2}\right)$ & $12.3(0-299)$ & $18.3(0-72.8)$ & $0(0-50)$ & NS \\
\hline Vv (sm/subepithelium) & $0.20(0-0.65)$ & $0.06(0-0.3)$ & $0.09(0-0.16)$ & 0.002 \\
\hline
\end{tabular}

Values are median (range).

All highlighted $p$ values denote difference between severe asthma and controls.

BAL, bronchoalveolarlavage; RBM, reticular basement membrane; sm, smooth muscle; Vv, volume fraction of airway smooth muscle indexed to subepithelium.

Conclusions Children with SA have increased luminal and submucosal eosinophilia. However, in contrast to reports in adults of AHR being associated with mast cell myositis, we have found severe asthmatic children with mast cell myositis were more likely to have PAL. Mast cell myositis may be a feature of severe asthma in children.

\section{Basic mechanisms in lung cancer S89 BIMODAL IRON OXIDE NANOPARTICLES FOR HYPERTHERMIA THERAPY AND MR IMAGING IN CANCER}

doi:10.1136/thx.2010.150938.40

${ }^{1} \mathrm{~K}$ L Parcell, ${ }^{1} \mathrm{~T}$ L Kalber, ${ }^{2} \mathrm{~S}$ Walker-Samuel, ${ }^{3} \mathrm{P}$ Southern, ${ }^{3} \mathrm{O}$ A Pankhurst, ${ }^{2} \mathrm{M} F$ Lythgoe, ${ }^{1} \mathrm{~S} M$ Janes. ${ }^{1}$ UCL Centre for Respiratory Research, London, UK; ${ }^{2}$ UCL Centre for Advanced Biomedical Imaging, London, UK; ${ }^{3}$ Davy-Faraday Research Laboratories, The Royal Institution of Great Britain, London, UK

Introduction Super paramagnetic iron oxide nanoparticles (SPION) offer attractive possibilities in biomedicine. Hyperthermia treatment of cancer involves introducing SPION into tumours and applying an alternating magnetic field (AMF). The AMF causes the SPION to heat, resulting in cell death. It has been shown previously that mesenchymal stem cells (MSCs) can be labelled with SPION, with no effect on cell survival, and that they will migrate to and integrate into lung metastases in vivo, following systemic administration. Furthermore, SPION can be used to follow the fate of labelled cells in the body as they cause a marked shortening in T2* on MRI. Therefore, MSCs labelled with SPION offer a promising delivery mechanism for treating lung metastases with hyperthermia therapy. In this preliminary study, the distribution of SPION labelled MSCs and the anti-tumour effect of hyperthermia treatment was evaluated in vitro and in a subcutaneous murine tumour model.

\section{Methods}

- MSCs were obtained from Tulane University, New Orleans. Cells were incubated overnight in $0.5 \mathrm{mg} / \mathrm{ml}$ of the SPION 